\title{
Nanotoxicology and oxidative stress control: cutting-edge topics in toxicology
}

\author{
H. M. Bolt · R. Marchan · J. G. Hengstler
}

(C) Springer-Verlag Berlin Heidelberg 2012

Every summer, the editors of the Archives of Toxicology analyse their most cited articles from the previous 2 years. Topping this year's list as the most cited original article is the pharmacokinetic and biodistribution study on silica nanoparticles (Xie et al. 2010). This study demonstrates that silica nanoparticles are retained for more than 30 days in various organs of mice (Table 1). The high interest and citation rates of this systematic biodistribution study illustrate the importance and relevance of nanoparticles to the field of toxicology today. The second most cited original article is the study by Drobná et al. (2010) on the metabolism and transport of inorganic arsenic. The high interest generated by the results of this study is not surprising. Arsenic poisoning, as a result of drinking water from contaminated wells, represents one of the largest man-made catastrophes in recent history (Golka et al. 2010). A study on the mechanism of action of silver nanoparticles ranks third in this citation analysis (Table 1).
In addition to original work, review articles were also included into our analysis. In the last 2 years, the most cited review, and coincidentally the most cited article, proposed a systems biology concept of an autocatalytic generation of oxidative stress, which is intensified by positive feedback loops and plays a central role in several degenerative diseases and toxic insults (Kell 2010). Following the review of Kell et al. is a comprehensive summary of the mechanisms of action and toxicological relevance of the mycotoxin, deoxynivalenol, also named 'vomitoxin' (Pestka 2010). The review of Adler et al. (2011) on in vitro systems ranks third, illustrating that the development of alternative methods currently represents a cutting-edge topic in toxicology.

The present citation analysis does not, by any means, represent a ranking of the scientific quality of our articles. However, it identifies the fields of research that attract the most attention and, therefore, may be a sensitive indicator of how our discipline could evolve in the future.

H. M. Bolt $(\varangle) \cdot$ R. Marchan · J. G. Hengstler 
Table 1 Key messages of the most cited articles in Arch Toxicol (2010-2011)

Key messages

Many degenerative diseases and toxicological insults converge on iron dysregulation. This review summarises several concepts of autocatalytic production of hydroxyl radicals-a process intensified by positive feedback loops. Systems biology approaches predict that interventions with, for example, iron chelators and antioxidants may prove most effective in diseases such as Parkinson's, Huntington's, Alzheimer's, prions as well as various forms of intoxications. The comprehensive review is the most cited article of the current evaluation period (2010-2011)

The trichothecene mycotoxin deoxynivalenol (DON) is produced by the fungus Fusarium in wheat and corn. This review summarises the molecular mechanisms of DON, which include ribotoxic stress, disturbed protein synthesis, compromised cell signalling, differentiation and proliferation. Proinflammatory gene induction, disruption of the growth hormone axis and altered gut integrity finally lead to gastroenteritis (vomitoxin), anorexia, immunotoxicity and impaired reproduction in experimental animals. This review is the second most cited article of this evaluation period

This review summarises the state of the art of in vitro toxicity tests in five critical fields of toxicity: toxicokinetics, repeated-dose toxicity, carcinogenicity, skin sensitisation and reproductive toxicity. The background of this review stems from the prohibition of animal-tested cosmetics on the market in Europe after 2013. The status and perspectives of each field are carefully analysed. For example, for skin sensitisation, in vitro techniques may already be able to identify sensitisers ahead of 2017. However, in other fields, particularly carcinogenesis, repeated-dose toxicity and reproductive toxicity, a time frame for in vitro alternatives cannot yet be estimated. This comprehensive review ranked third in the current evaluation period

Silica nanoparticles (SiNPs) are widely developed for biomedical applications. This study quantitatively analysed the time-dependent tissue and subcellular distribution of SiNPs in mice, including radioactive counting, transmission electron microscopy and histology. SiNPs that accumulate in lungs, liver and spleen are retained for more than 30 days. These particles are endocytosed by macrophages and could cause liver toxicity. This is the most cited original article of the current evaluation period. It underlines the emergence of nanotoxicology as one of the most popular fields in toxicology

Metabolism of inorganic arsenic (iAs) is critical for its toxicity. This study analysed the relevance of arsenic transporters on human hepatocytes for the generation of methylated metabolites from iAs. A major finding is that MRP2 expression inversely correlates with cellular retention of iAs, as well as methylated metabolites in hepatocytes. This suggests that MRP2 plays an important role in the efflux of iAs and its metabolites. This study is the second most cited original article from the evaluation period

The comprehensive review article gives an overview of mutagenicity and carcinogenicity studies on selenium, and discusses the molecular mechanisms involved. At low concentrations, selenium shows anticarcinogenic effects. However, at concentrations higher than needed for nutrition, selenium proves to be genotoxic and carcinogenic. This study may help regulate the use of selenium in nutrition

Silver nanoparticles (AgNPs) caused a concentration-dependent increase in reactive oxygen species (ROS), mitochondrial damage, DNA adducts and apoptosis in a human alveolar cell line. Pre-treatment with antioxidants reduced ROS as well as DNA adducts underlining the relevance of ROS in toxicity of AgNPs. This study ranks third among the most cited original articles

Metabolomics have successfully identified novel biomarkers of disease prognosis and drug efficacy as well as toxicity. This review summarises how novel biomarkers discovered by metabolomics should be verified and introduced into clinical practice

This review focusses on the following aspects of selenium toxicity: (1) The majority of epidemiological studies suggest a cancer-preventing activity. (2) In cancer treatment, selenium acts as a pro-oxidant by inducing apoptosis. (3) The use of Saccharomyces cerevisiae is reviewed as a powerful tool to study the mode of action of selenium

Ammonium perfluorooctanoate, used in the production of fluoropolymers, induces hepatocellular hypertrophy in rats by activation of the nuclear receptors, PPAR alpha and CAR/PXR

Formaldehyde causes nasal cancer and lymphohematopoietic malignancies (LHM) in laboratory animals. Nasal cancer seems to be associated with cytotoxicity-induced proliferation. LHM occurs at even higher doses than nasal cancer. This study discusses the guideline value of $0.08 \mathrm{ppm}$ formaldehyde to prevent carcinogenic effects

(1,3)-Beta-D-glucan, which occurs on damp building materials, induces an inflammation-associated gene transcription profile in mouse lungs

This review discusses the future perspectives of organoselenium as pharmacological agents. It also focuses on epidemiological evidence that selenium overexposure leads to chronic degenerative diseases

This is a comprehensive review on the protective network controlled by the Keap1-Nrf2 axis, focussing on proliferation, angiogenesis and apoptosis
References

(1)

Kell (2010)

Pestka (2010)

Adler et al. (2011)

Xie et al. (2010)

Drobná et al. (2010)

Valdiglesias et al. (2010)

(7)

Foldbjerg et al. (2011)

(8)

Mamas et al. (2011)

Brozmanová et al. (2010)

Elcombe et al. (2010)

(11)

Nielsen and Wolkoff (2010)

Rand et al. (2010)

Nogueira and Rocha (2011)

Baird and Dinkova-Kostova (2011) 
Table 1 continued

Key messages

This review on Nrf2 focusses on the relevance of Nrf2 disruption in colon, bladder, lung, stomach, breast, skin and liver cancers

This review gives an overview on how arsenate and arsenite interfere with intracellular signal transduction networks

High brain concentrations of the organoselenium compound, diphenyl diselenide, are associated with shorter time to seizure episodes in rats

The development of Parkinson's disease following exposure to welding fumes is an area of growing concern.

This study demonstrates that repeated exposure of rats to manganese-containing welding fumes causes persistent alterations in dopaminergic targets

Recent studies suggest that inhaled nanoparticles from diesel engine exhaust may also reach the brain. This study demonstrates that the inhalation of diesel engine exhaust by rats causes region-specific gene expression changes in the brain that is comparable to that observed in the lung

Phosphorylated butyrylcholinesterase and phosphorylated albumin were compared as biomarkers of organophosphorus exposure

This review gives a comprehensive update of the micronucleus assay, including its toxicological relevance, protocols, application as a high-throughput assay and mechanisms of micronucleus formation

The comprehensive review gives an overview of the use of human pluripotent stem cells, embryonic stem cells and induced pluripotent stem cells in developmental, cardio- and hepato-toxicity testing

Furan is formed during thermal treatment of food and is consistently found in baby foods. It induces both hepatocellular and bile duct tumours in rodents. This review gives a thorough risk assessment of furan in human diet

The liver tumour promoter piperonyl butoxide generates reactive oxygen species which increase c-Myc- and E2F1-related pathways and thereby activate cell proliferation

Oxidative stress alone is not sufficient to explain specific mechanisms induced by nanoparticles. This article addresses nanoparticle-induced activation of MAP kinase cascades, p38, JNK, NF-kappa B and Nrf2 signalling pathways

Flavonoids have been reported to provide neuroprotection. However, this article provides evidence of a more complex situation: Both quercetin and quercitrin protected the mitochondria of rat brain slices from $\mathrm{MeHg}$ induced lipid peroxidation. In contrast, rutin was not protective. $\mathrm{Ca}^{2+}$ plays a central role in $\mathrm{MeHg}$-induced toxicity

Silica nanoparticles $\left(\mathrm{SiO}_{2}\right.$-NPs) were found in the endosomes and the cytosol of HeLa cells. No accumulation in mitochondria or nuclei was seen. In contrast, the larger 'submicron particles' (SiO2-SMPs) accumulated in lysosomes

A single-nucleotide polymorphism, rs710521[A], located near TP63, and recently discovered in genome-wide association studies, was associated with human bladder cancer risk in a case-control series of 1,425 cases and 1,740 controls

The pyrethroid insecticide, cypermethrin disrupts testosterone synthesis in testes of mice

The capping material of nanocrystal quantum dots, and not the material of the core, determines toxicity

The toxicokinetics of thiomersal is completely different from that of methylmercury. Therefore, toxicity data from methylmercury studies are not appropriate when assessing the risk from mercury released from the ethylmercury-releasing preservative, thiomersal

Perfluorooctane (PFOS) is a bioaccumulative pollutant. In rat brain tissue, PFOS activates calcium signalling and c-Fos, as well as c-Jun

This study applied a genotoxicity assay based on the detection of histone H2AX phosphorylation to compare bisphenol A and bisphenol F. Bisphenol A was not found to be genotoxic, whereas bisphenol F showed positive effects

Sodium fluoride suppresses proliferation and induces apoptosis in cultivated osteoblasts. This effect was caused by decreased insulin-like growth factor-1 expression

The flavonoid quercetin protects against methylmercury-induced DNA damage and oxidative stress in rats
References

(15)

Slocum and Kensler (2011)

(16)

Druwe and Vaillancourt

(17)

Prigol et al. (2010)

(18)

Sriram et al. (2010)

van Berlo et al. (2010)

(20)

Read et al. (2010)

(21)

Kirsch-Volders et al. (2011)

Wobus and Löser (2011)

Bakhiya and Appel (2010)

Kawai et al. (2010)

Marano et al. (2011)

(26)

Wagner et al. (2010)

Al-Rawi et al. (2011)

Lehmann et al. (2010)

Wang et al. (2010)

(30)

Hoshino et al. (2011)

(31)

Rodrigues et al. (2010)

(32)

Liu et al. (2010a, b)

(33)

Audebert et al. (2011)

Wang et al. (2011)

(35)

Barcelos et al. (2011) 
Table 1 continued

Key messages

This review discussed the current possibilities and perspectives of in vitro test systems for nanotoxicology

The aspect ratio (defined as the ratio length: diameter) of carbon nanotubes has no influence on genotoxicity

Inorganic arsenic induces apoptosis in the cerebrum of mice

Increasing age leads to alterations of hepatic cytochrome P450 isoforms in rats. CYP1A1, CYP1A2, CYP2B1 and CYP2E1 were maximally expressed at 3 weeks, and then later decreased

This review gives an update on the mechanisms of action and cellular targets of toxic metals, as well as the use of chelating agents for pharmaceutical treatment

This review summarises epidemiological studies on maternal exposure to particulate matters and adverse pregnancy outcomes. Overall, there is no convincing evidence of an association

Transition metal ions induce lipid peroxidation in artificial phospholipid liposomes

The antioxidants, isoquercitrin and melatonin reduce oxidative stress-mediated liver tumour promotion by the benzimidazole anthelmintic, oxfendazole in rats

Administration of silver nanoparticles to rats caused a dose-dependent accumulation of particles in the lamina propria of the small and large intestine, increased numbers of goblet cells and altered mucus composition

The author critically discusses Hermann J. Muller's well-known Nobel lecture where a linear dose-response for radiation-induced germ cell mutations was presented. In contrast to this concept, Calabrese presents arguments speaking against the linear no-threshold model

Zinc oxide nanoparticles induce the release of pro-inflammatory cytokines in mouse and human cell systems

A single intratracheal instillation of carbon nanotubes may induce early lung fibrosis

Indole-3-carbinol and flutamide increased the expression of CYP1A1 and induced liver cell foci in rats

Synephrine is added to dietary supplements for weight loss. The hydroxyl group in the p-position favours transporter-mediated uptake into cardiomyocytes. Moreover, isomerisation of synephrine influences its toxicological profile

DNA strand breaks induced by platinum nanoparticles are mediated by platinum ions released from the nanoparticles

This review deals with the description and comparison of cyclotron-based irradiation techniques for the generation of radiolabelled nanoparticles applicable in nanotoxicity tracing approaches

In urinary bladder cancer, all known validated individual SNPs are associated with only a moderate risk that is too low to justify preventive measures. The authors review this issue and propose that these so-called wimp SNPs may interact and, therefore, collectively result in much higher risk with preventive relevance

The genotoxic potential of dental composite components, such as bis-GMA, TEGDMA, HEMA and MMA, was studied in gingival fibroblasts. It was found that DNA strand breaks comparable to those induced by irradiation are only achieved with unrealistic concentrations

Elevated expression of Th2 cytokines and signal molecules during the inflammation response in silica-induced pulmonary fibrosis in mice is mediated by IL-6R alpha

This study shows that beta-carboline alkaloids, such as rutaecarpine, annomontine and xestomanzamine A, are stimulators of AhR and lead to AhR-targeted gene expression

Possible oestrogenic effects of cadmium were analysed in the rat intestine. Cadmium exposure was shown to modulate molecular and functional parameters of oestrogenicity, such as proliferation and expression of the oestrogen-regulated gene ER beta

Exposure to the commercial formulation of the herbicide glyphosate during puberty disrupts the reproductive development of rats by altering testosterone level and testicular morphology
References

Clift et al. (2011)

(37)

Kim et al. (2011)

(38)

Yen et al. (2011)

(39)

Yun et al. (2010)

(40)

Sinicropi et al. (2010)

(41)

Bosetti et al. (2010)

(42)

Repetto et al. (2010)

(43)

Nishimura et al. (2010)

(44)

Jeong et al. (2010)

(45)

Calabrese (2011)

Heng et al. (2011)

(47)

Park et al. (2011)

(48)

Shimamoto et al. (2011)

Rossato et al. (2011)

Gehrke et al. (2011)

(51)

Gibson et al. (2011)

(52)

Golka et al. (2011)

(53)

Durner et al. (2011)

(54)

Tripathi et al. (2010)

(55)

Haarmann-Stemmann et al. (2010)

(56)

Höfer et al. (2010)

Romano et al. (2010) 
Table 1 continued

Key messages $\quad$ References

Gene expression alterations in the brains of neonatal mice exposed to methylmercury and polychlorinated biphenyls, alone or in combination, reveal not only toxicity effects but also a protective detoxification response upon co-exposure

Perinatal exposure to perfluorooctane sulphonate during the critical period of brain development may have neurotoxic effects on the CNS by altering the expression of calcium-dependent signalling pathway molecules

An overview of the currently available metabolic databases is given, with the MetaCyc family being described in particular detail

(58)

Shimada et al. (2010)

Liu et al. (2010a, b)

(60)

Karp and Caspi (2011)

\section{References}

Adler S, Basketter D, Creton S, Pelkonen O, van Benthem J, Zuang V, Andersen KE, Angers-Loustau A, Aptula A, Bal-Price A, Benfenati E, Bernauer U, Bessems J, Bois FY, Boobis A, Brandon E, Bremer S, Broschard T, Casati S, Coecke S, Corvi R, Cronin M, Daston G, Dekant W, Felter S, Grignard E, GundertRemy U, Heinonen T, Kimber I, Kleinjans J, Komulainen H, Kreiling R, Kreysa J, Leite SB, Loizou G, Maxwell G, Mazzatorta P, Munn S, Pfuhler S, Phrakonkham P, Piersma A, Poth A, Prieto P, Repetto G, Rogiers V, Schoeters G, Schwarz M, Serafimova R, Tähti H, Testai E, van Delft J, van Loveren H, Vinken M, Worth A, Zaldivar JM (2011) Alternative (nonanimal) methods for cosmetics testing: current status and future prospects-2010. Arch Toxicol 85(5):367-485

Al-Rawi M, Diabaté S, Weiss C (2011) Uptake and intracellular localization of submicron and nano-sized $\mathrm{SiO}_{2}$ particles in $\mathrm{HeLa}$ cells. Arch Toxicol 85(7):813-826

Audebert M, Dolo L, Perdu E, Cravedi JP, Zalko D (2011) Use of the $\gamma \mathrm{H} 2 \mathrm{AX}$ assay for assessing the genotoxicity of bisphenol A and bisphenol F in human cell lines. Arch Toxicol 85(11):1463-1473

Baird L, Dinkova-Kostova AT (2011) The cytoprotective role of the Keap1-Nrf2 pathway. Arch Toxicol 85(4):241-272

Bakhiya N, Appel KE (2010) Toxicity and carcinogenicity of furan in human diet. Arch Toxicol 84(7):563-578

Barcelos GR, Grotto D, Serpeloni JM, Angeli JP, Rocha BA, de Oliveira Souza VC, Vicentini JT, Emanuelli T, Bastos JK, Antunes LM, Knasmüller S, Barbosa F Jr (2011) Protective properties of quercetin against DNA damage and oxidative stress induced by methylmercury in rats. Arch Toxicol 85(9): $1151-1157$

Bosetti C, Nieuwenhuijsen MJ, Gallus S, Cipriani S, La Vecchia C, Parazzini F (2010) Ambient particulate matter and preterm birth or birth weight: a review of the literature. Arch Toxicol 84(6): $447-460$

Brozmanová J, Mániková D, Vlčková V, Chovanec M (2010) Selenium: a double-edged sword for defense and offence in cancer. Arch Toxicol 84(12):919-938

Calabrese EJ (2011) Muller's Nobel lecture on dose-response for ionizing radiation: ideology or science? Arch Toxicol 85(12): $1495-1498$

Clift MJ, Gehr P, Rothen-Rutishauser B (2011) Nanotoxicology: a perspective and discussion of whether or not in vitro testing is a valid alternative. Arch Toxicol 85(7):723-731

Drobná Z, Walton FS, Paul DS, Xing W, Thomas DJ, Stýblo M (2010) Metabolism of arsenic in human liver: the role of membrane transporters. Arch Toxicol 84(1):3-16

Druwe IL, Vaillancourt RR (2010) Influence of arsenate and arsenite on signal transduction pathways: an update. Arch Toxicol 84(8):585-596

Durner J, Dębiak M, Bürkle A, Hickel R, Reichl FX (2011) Induction of DNA strand breaks by dental composite components compared to X-ray exposure in human gingival fibroblasts. Arch Toxicol 85(2):143-148

Elcombe CR, Elcombe BM, Foster JR, Farrar DG, Jung R, Chang SC, Kennedy GL, Butenhoff JL (2010) Hepatocellular hypertrophy and cell proliferation in Sprague-Dawley rats following dietary exposure to ammonium perfluorooctanoate occurs through increased activation of the xenosensor nuclear receptors PPAR $\alpha$ and CAR/PXR. Arch Toxicol 84(10):787-798

Foldbjerg R, Dang DA, Autrup H (2011) Cytotoxicity and genotoxicity of silver nanoparticles in the human lung cancer cell line, A549. Arch Toxicol 85(7):743-750

Gehrke H, Pelka J, Hartinger CG, Blank H, Bleimund F, Schneider R, Gerthsen D, Bräse S, Crone M, Türk M, Marko D (2011) Platinum nanoparticles and their cellular uptake and DNA platination at non-cytotoxic concentrations. Arch Toxicol 85(7):799-812

Gibson N, Holzwarth U, Abbas K, Simonelli F, Kozempel J, Cydzik I, Cotogno G, Bulgheroni A, Gilliland D, Ponti J, Franchini F, Marmorato P, Stamm H, Kreyling W, Wenk A, SemmlerBehnke M, Buono S, Maciocco L, Burgio N (2011) Radiolabelling of engineered nanoparticles for in vitro and in vivo tracing applications using cyclotron accelerators. Arch Toxicol 85(7):751-773

Golka K, Hengstler JG, Marchan R, Bolt HM (2010) Severe arsenic poisoning: one of the largest man-made catastrophies. Arch Toxicol 84(8):583-584

Golka K, Selinski S, Lehmann ML, Blaszkewicz M, Marchan R, Ickstadt K, Schwender H, Bolt HM, Hengstler JG (2011) Genetic variants in urinary bladder cancer: collective power of the "wimp SNPs". Arch Toxicol 85(6):539-554

Haarmann-Stemmann T, Sendker J, Götz C, Krug N, Bothe H, Fritsche E, Proksch P, Abel J (2010) Regulation of dioxin receptor function by different beta-carboline alkaloids. Arch Toxicol 84(8):619-629

Heng BC, Zhao X, Tan EC, Khamis N, Assodani A, Xiong S, Ruedl C, Ng KW, Loo JS (2011) Evaluation of the cytotoxic and inflammatory potential of differentially shaped zinc oxide nanoparticles. Arch Toxicol 85(12):1517-1528

Höfer N, Diel P, Wittsiepe J, Wilhelm M, Kluxen FM, Degen GH (2010) Investigations on the estrogenic activity of the metallohormone cadmium in the rat intestine. Arch Toxicol 84(7): $579-581$

Hoshino A, Hanada S, Yamamoto K (2011) Toxicity of nanocrystal quantum dots: the relevance of surface modifications. Arch Toxicol 85(7):707-720

Jeong J, Han BS, Cho WS, Choi M, Ha CS, Lee BS, Kim YB, Son WC, Kim CY (2010) Carcinogenicity study of 3-monochloropropane-1, 2-diol (3-MCPD) administered by drinking water to B6C3F1 mice showed no carcinogenic potential. Arch Toxicol 84(9):719-729

Karp PD, Caspi R (2011) A survey of metabolic databases emphasizing the MetaCyc family. Arch Toxicol 85(9):1015-1033 
Kawai M, Saegusa Y, Dewa Y, Nishimura J, Kemmochi S, Harada T, Ishii Y, Umemura T, Shibutani M, Mitsumori K (2010) Elevation of cell proliferation via generation of reactive oxygen species by piperonyl butoxide contributes to its liver tumorpromoting effects in mice. Arch Toxicol 84(2):155-164

Kell DB (2010) Towards a unifying, systems biology understanding of large-scale cellular death and destruction caused by poorly liganded iron: Parkinson's, Huntington's, Alzheimer's, prions, bactericides, chemical toxicology and others as examples. Arch Toxicol 84(11):825-889

Kim JS, Lee K, Lee YH, Cho HS, Kim KH, Choi KH, Lee SH, Song KS, Kang CS, Yu IJ (2011) Aspect ratio has no effect on genotoxicity of multi-wall carbon nanotubes. Arch Toxicol 85(7):775-786

Kirsch-Volders M, Plas G, Elhajouji A, Lukamowicz M, Gonzalez L, Vande Loock K, Decordier I (2011) The in vitro MN assay in 2011: origin and fate, biological significance, protocols, high throughput methodologies and toxicological relevance. Arch Toxicol 85(8):873-899

Lehmann ML, Selinski S, Blaszkewicz M, Orlich M, Ovsiannikov D, Moormann O, Guballa C, Kress A, Truss MC, Gerullis H, Otto T, Barski D, Niegisch G, Albers P, Frees S, Brenner W, Thüroff JW, Angeli-Greaves M, Seidel T, Roth G, Dietrich H, Ebbinghaus R, Prager HM, Bolt HM, Falkenstein M, Zimmermann A, Klein T, Reckwitz T, Roemer HC, Löhlein D, Weistenhöfer W, Schöps W, Beg AE, Aslam M, Bánfi G, Romics I, Ickstadt K, Schwender H, Winterpacht A, Hengstler JG, Golka K (2010) Rs710521[A] on chromosome 3q28 close to TP63 is associated with increased urinary bladder cancer risk. Arch Toxicol 84:967-978

Liu X, Liu W, Jin Y, Yu W, Liu L, Yu H (2010a) Effects of subchronic perfluorooctane sulfonate exposure of rats on calcium-dependent signaling molecules in the brain tissue. Arch Toxicol 84(6):471-479

Liu X, Liu W, Jin Y, Yu W, Wang F, Liu L (2010b) Effect of gestational and lactational exposure to perfluorooctanesulfonate on calcium-dependent signaling molecules gene expression in rats' hippocampus. Arch Toxicol 84(1):71-79

Mamas M, Dunn WB, Neyses L, Goodacre R (2011) The role of metabolites and metabolomics in clinically applicable biomarkers of disease. Arch Toxicol 85(1):5-17

Marano F, Hussain S, Rodrigues-Lima F, Baeza-Squiban A, Boland S (2011) Nanoparticles: molecular targets and cell signalling. Arch Toxicol 85(7):733-741

Nielsen GD, Wolkoff P (2010) Cancer effects of formaldehyde: a proposal for an indoor air guideline value. Arch Toxicol 84(6):423-446

Nishimura J, Saegusa Y, Dewa Y, Jin M, Kawai M, Kemmochi S, Harada T, Hayashi SM, Shibutani M, Mitsumori K (2010) Antioxidant enzymatically modified isoquercitrin or melatonin supplementation reduces oxidative stress-mediated hepatocellular tumor promotion of oxfendazole in rats. Arch Toxicol 84(2): 143-153

Nogueira CW, Rocha JB (2011) Toxicology and pharmacology of selenium: emphasis on synthetic organoselenium compounds. Arch Toxicol 85(11):1313-1359

Park EJ, Roh J, Kim SN, Kang MS, Han YA, Kim Y, Hong JT, Choi K (2011) A single intratracheal instillation of single-walled carbon nanotubes induced early lung fibrosis and subchronic tissue damage in mice. Arch Toxicol 85(9):1121-1131

Pestka JJ (2010) Deoxynivalenol: mechanisms of action, human exposure, and toxicological relevance. Arch Toxicol 84(9):663-679

Prigol M, Pinton S, Schumacher R, Nogueira CW, Zeni G (2010) Convulsant action of diphenyl diselenide in rat pups: measurement and correlation with plasma, liver and brain levels of compound. Arch Toxicol 84(5):373-378
Rand TG, Sun M, Gilyan A, Downey J, Miller JD (2010) Dectin-1 and inflammation-associated gene transcription and expression in mouse lungs by a toxic (1,3)-beta-D glucan. Arch Toxicol 84(3):205-220

Read RW, Riches JR, Stevens JA, Stubbs SJ, Black RM (2010) Biomarkers of organophosphorus nerve agent exposure: comparison of phosphylated butyrylcholinesterase and phosphylated albumin after oxime therapy. Arch Toxicol 84(1):25-36

Repetto MG, Ferrarotti NF, Boveris A (2010) The involvement of transition metal ions on iron-dependent lipid peroxidation. Arch Toxicol 84(4):255-262

Rodrigues JL, Serpeloni JM, Batista BL, Souza SS, Barbosa F Jr (2010) Identification and distribution of mercury species in rat tissues following administration of thimerosal or methylmercury. Arch Toxicol 84(11):891-896

Romano RM, Romano MA, Bernardi MM, Furtado PV, Oliveira CA (2010) Prepubertal exposure to commercial formulation of the herbicide glyphosate alters testosterone levels and testicular morphology. Arch Toxicol 84(4):309-317

Rossato LG, Costa VM, de Pinho PG, Carvalho F, de Lourdes Bastos M, Remião F (2011) Structural isomerization of synephrine influences its uptake and ensuing glutathione depletion in ratisolated cardiomyocytes. Arch Toxicol 85(8):929-939

Shimada M, Kameo S, Sugawara N, Yaginuma-Sakurai K, Kurokawa N, Mizukami-Murata S, Nakai K, Iwahashi H, Satoh H (2010) Gene expression profiles in the brain of the neonate mouse perinatally exposed to methylmercury and/or polychlorinated biphenyls. Arch Toxicol 84(4):271-286

Shimamoto K, Dewa Y, Kemmochi S, Taniai E, Hayashi H, Imaoka M, Shibutani M, Mitsumori K (2011) Relationship between CYP1A induction by indole-3-carbinol or flutamide and liver tumorpromoting potential in rats. Arch Toxicol 85(9):1159-1166

Sinicropi MS, Amantea D, Caruso A, Saturnino C (2010) Chemical and biological properties of toxic metals and use of chelating agents for the pharmacological treatment of metal poisoning. Arch Toxicol 84(7):501-520

Slocum SL, Kensler TW (2011) Nrf2: control of sensitivity to carcinogens. Arch Toxicol 85(4):273-284

Sriram K, Lin GX, Jefferson AM, Roberts JR, Chapman RS, Chen BT, Soukup JM, Ghio AJ, Antonini JM (2010) Dopaminergic neurotoxicity following pulmonary exposure to manganesecontaining welding fumes. Arch Toxicol 84(7):521-540

Tripathi SS, Mishra V, Shukla M, Verma M, Chaudhury BP, Kumar P, Chhabra JK, Pandey HP, Paul B (2010) IL-6 receptor-mediated lung Th2 cytokine networking in silica-induced pulmonary fibrosis. Arch Toxicol 84(12):947-955

Valdiglesias V, Pásaro E, Méndez J, Laffon B (2010) In vitro evaluation of selenium genotoxic, cytotoxic, and protective effects: a review. Arch Toxicol 84(5):337-351

van Berlo D, Albrecht C, Knaapen AM, Cassee FR, Gerlofs-Nijland ME, Kooter IM, Palomero-Gallagher N, Bidmon HJ, van Schooten FJ, Krutmann J, Schins RP (2010) Comparative evaluation of the effects of short-term inhalation exposure to diesel engine exhaust on rat lung and brain. Arch Toxicol 84(7):553-562

Wagner C, Vargas AP, Roos DH, Morel AF, Farina M, Nogueira CW, Aschner M, Rocha JB (2010) Comparative study of quercetin and its two glycoside derivatives quercitrin and rutin against methylmercury $(\mathrm{MeHg}$ )-induced ROS production in rat brain slices. Arch Toxicol 84(2):89-97

Wang H, Wang Q, Zhao XF, Liu P, Meng XH, Yu T, Ji YL, Zhang H, Zhang C, Zhang Y, Xu DX (2010) Cypermethrin exposure during puberty disrupts testosterone synthesis via downregulating StAR in mouse testes. Arch Toxicol 84(1):53-61

Wang Z, Yang X, Yang S, Ren G, Ferreri M, Su Y, Chen L, Han B (2011) Sodium fluoride suppress proliferation and induce 
apoptosis through decreased insulin-like growth factor-I expression and oxidative stress in primary cultured mouse osteoblasts. Arch Toxicol 85(11):1407-1417

Wobus AM, Löser P (2011) Present state and future perspectives of using pluripotent stem cells in toxicology research. Arch Toxicol 85(2):79-117

Xie G, Sun J, Zhong G, Shi L, Zhang D (2010) Biodistribution and toxicity of intravenously administered silica nanoparticles in mice. Arch Toxicol 84(3):183-190
Yen CC, Ho TJ, Wu CC, Chang CF, Su CC, Chen YW, Jinn TR, Lu TH, Cheng PW, Su YC, Liu SH, Huang CF (2011) Inorganic arsenic causes cell apoptosis in mouse cerebrum through an oxidative stress-regulated signaling pathway. Arch Toxicol 85(6):565-575

Yun KU, Oh SJ, Oh JM, Kang KW, Myung CS, Song GY, Kim BH, Kim SK (2010) Age-related changes in hepatic expression and activity of cytochrome P450 in male rats. Arch Toxicol 84(12): 939-946 